\title{
Effects of Cimetidine on Prostanoid Production in the Gastric Corpus Specimens from Rats
}

\author{
Kazuhiko KUBOTA, Kiminobu SUGAYA and Kyoko HOTTA ${ }^{1}$ \\ Department of Pharmacology. Faculty of Pharmaceutical Sciences. \\ Science University of Tokyo, Shinjuku-ku, Tokyo 162, Japan \\ ${ }^{1}$ Department of Biochemistry and Internal Medicine. Kitasato University \\ School of Medicine. Sagamihara, Kanagawa 228, Japan
}

Accepted September 24, 1988

\begin{abstract}
In order to examine the effect of cimetidine on the production of prostanoids in the stomach mucosa, the amounts of prostaglandin $(P G) E_{2}, F_{1 \alpha}$ and thromboxane (TX) $B_{2}$ were determined after the specimens from the rat stomach corpus were incubated in the presence of cimetidine. Cimetidine significantly stimulated the production of $P \mathrm{PE}_{2}$ in the specimens at a concentration of $10 \mu \mathrm{M}$, but did not significantly affect the production of $\mathrm{PGF}_{1 \alpha}$ and $\mathrm{TXB}_{2}$ at concentrations of 1 to $100 \mu \mathrm{M}$.
\end{abstract}

Cimetidine, a well-known $\mathrm{H}_{2}$-antagonist has been widely used clinically for treating peptic ulcer. There is no doubt that the major antiulcer effect of cimetidine is the inhibition of gastric acid secretion. Recently however, in addition to the inhibition of gastric acid, the possibility that cimetidine has a cytoprotective action has also been suggested. For example, cimetidine prevented the gastric lesion of rats induced by aspirin plus $0.15 \mathrm{~N} \mathrm{HCl}$ (1). On the other hand, prostaglandin (PG) $E$ and $A$ and prostacyclin have been shown to be strong inhibitors of gastric acid secretion $(2-4)$. On the basis of these findings, the effects of cimetidine on the prostanoid synthesis in the gastric mucosa have been examined (5-7), but the results so far reported are contradictory.

In this paper, the authors examined whether cimetidine enhances prostanoid synthesis in the cultured rat stomach corpus.

Male Wistar rats weighing 152-167 g were used. The animals that had been fasted for 12 hr before the experiments were killed by exsanguination from the carotid artery, and their stomachs were excised and washed in $\mathrm{Ca}^{2+} / \mathrm{Mg}^{2+}$-free phosphate-buffered saline. The stomach corpus was cut in approximately $4 \mathrm{~mm}^{2}$ specimens under a microscope.

The culture method of Eastwood and Trier
(8) slightly modified according to Ohara et al. (9) was used. Four tissue specimens of the corpus were placed, with the mucosal surface facing upward, on a stainless steel grid which was hung over a small well placed in a plastic culture dish (Falcon Plastics, Los Angeles, CA, U.S.A.). The well was filled with $0.75 \mathrm{ml}$ of a culture medium consisting of $90 \%$ Eagle's minimum essential medium, $10 \%$ dialyzed fetal calf serum and $6 \mathrm{mg} / 100 \mathrm{ml}$ medium of tobramycin and maintained at $37^{\circ} \mathrm{C}$ for $3 \mathrm{hr}$ in $5 \% \mathrm{CO}_{2}$ and $95 \%$ humid air.

Cimetidine was dissolved in dimethyl sulfoxide and added to the culture medium in the well at concentrations of 1,10 and 100 $\mu \mathrm{M}$. The final concentration of dimethyl sulfoxide was $0.01 \%$ in the culture medium. The control culture medium contained $0.01 \%$ of dimethyl sulfoxide. At the end of the culture period, the culture medium was aspirated for the determination of prostanoids.

To determine $\mathrm{PGE}_{2}, \mathrm{PGF}_{1 \alpha}$ and thromboxane $(T X) B_{2}$ in the culture medium, $D u$ Pont PG [125I]-radioimmunoassay kits (E.I. du Pont de Nemours \& Co., Inc., NEN Products) were used. The radioactivity was measured by an Aloka ARC-300 auto-well $r$-system.

The results were expressed as the mean \pm S.E. of 6 experiments, and significant differ- 
Table 1. Effect of cimetidine on prostanoid synthesis in cultured corpus

\begin{tabular}{lllll} 
& & $\mathrm{PGE}_{2}(\mathrm{ng} / \mathrm{l})$ & $\mathrm{PGF}_{1 \alpha}(\mathrm{ng} / \mathrm{I})$ & $\mathrm{TXB}_{2}(\mathrm{ng} / \mathrm{I})$ \\
\cline { 2 - 4 } Cimetidine, $0 \mu \mathrm{M}$ & $369.1 \pm 24.12$ & $4352.0 \pm 268.80$ & $2588.8 \pm 126.65$ \\
Cimetidine, $1 \mu \mathrm{M}$ & $425.9 \pm 23.05$ & $3978.5 \pm 172.17$ & $2438.9 \pm 64.65$ \\
Cimetidine, $10 \mu \mathrm{M}$ & $472.8 \pm 18.63^{*}$ & $3918.9 \pm 219.45$ & $2367.8 \pm 118.44$ \\
Cimetidine, $100 \mu \mathrm{M}$ & $422.4 \pm 34.27$ & $4153.8 \pm 278.47$ & $2495.3 \pm 121.17$ \\
\hline
\end{tabular}

The amounts of prostanoids accumulated in each culture medium in which four corpus specimens were incubated were determined by radioimmunoassay as described in Materials and Methods. Figures in the table denote the mean $\pm S$.E. of 6 experiments. ${ }^{*}: P<0.05$ significant difference from the control (cimetidine, $0 \mu \mathrm{M}$ ) by Student's $t$-test.

ences of the means were assessed by Student's $t$-test.

The accumulation of $\mathrm{PGE}_{2}$ in the culture medium was dose-dependently increased by cimetidine in the range from 1 to $10 \mu \mathrm{M}$. Ten $\mu \mathrm{M}$ of cimetidine significantly increased the accumulation of $P G E_{2}$ as compared with that of the control, but $100 \mu \mathrm{M}$ of cimetidine tended to decrease the $\mathrm{PGE}_{2}$ as compared with that by $10 \mu \mathrm{M}$ of cimetidine.

On the other hand, cimetidine exerted no significant effect on the accumulation of $\mathrm{PGE}_{1 \alpha}$ and $\mathrm{TXB}_{2}$ in all concentrations used.

According to Arakawa et al. (6), cimetidine administered to rats twice a day for 7 days at a daily dose of $40 \mathrm{mg} / \mathrm{kg}$ decreased $P \mathrm{PE}_{2}$ and $\mathrm{PGF}_{1 \alpha}$ in the gastric mucosal tissue. By contrast, Branski et al. (5) reported that the accumulation of $\mathrm{PGE}_{2}$ and $P G F_{1 \alpha}$ in the biopsy specimens from the stomach of ulcer patients was significantly increased after 4 weeks of cimetidine treatment at a daily dose of $1 \mathrm{~g}$. Okada et al. (10) also showed that the PGE level in the gastric mucosa of rats exposed to restraint and water-immersion stress was elevated by $25 \mathrm{mg} / \mathrm{kg}$ of oral cimetidine.

In the present work, we used the stomach corpus specimens which included mucosa and muscle layers. The specimens were cultured for $3 \mathrm{hr}$ at $37^{\circ} \mathrm{C}$ in the absence or the presence of cimetidine, and the prostanoids secreted in the culture medium were determined. Under these conditions, cimetidine significantly increased the concentration of $P G E_{2}$ in the medium at $10 \mu \mathrm{M}$, although both the higher $(100 \mu \mathrm{M})$ and the lower $(1 \mu \mathrm{M})$ concentrations of cimetidine failed to increase $\mathrm{PGE}_{2}$ production. The reason for the bell-shaped dose-effect relation of cimetidine is not clear at present. The production of
$P G F_{1 \alpha}$ and $T X B_{2}$ was not significantly affected by cimetidine under the present conditions. It should be noted that the amount of $P \mathrm{PE}_{2}$ was much lower than those of $\mathrm{PGF}_{1 \alpha}$ and $T X B_{2}$ as shown in Table 1. We measured the amounts of these prostanoids in the incubation medium. According to Branski et al. (5), the accumulation of $\mathrm{PGF}_{1}$ and $\mathrm{TXB}_{2}$ in the medium by cultured biopsy specimens obtained from the stomach of ulcer patients was similar to that of $\mathrm{PGE}_{2}$. The discrepancy seems to come from the differences in animal species and experimental conditions. However, their results that only the $P G E_{2}$ production was increased by cimetidine are compatible with those obtained by the present work. Whether the increase in $\mathrm{PGE}_{2}$ by cimetidine is due to the blockade of $\mathrm{H}_{2}$ receptors is an interesting problem. Since ranitidine, another strong $\mathrm{H}_{2}$ blocker, does not significantly affect the gastric mucosal $P G E_{2}$ in rats (11), the effect of cimetidine on $P G E_{2}$ production seems to be exerted by some actions other than its $\mathrm{H}_{2}$ blocking action. In the present experiments, specimens were incubated in a culture medium, suggesting that the acid produced by the mucosa will have little effect on the prostanoid production.

\section{References}

1 Kauffman, G.L., Jr. and Grossman, M.I.: Prostaglandin and cimetidine inhibit the formation of ulcers produced by parenteral salicylates. Gastroenterology 75, 1099-1102 (1978)

2 Main, I.H.M. and Whittle, B.J.R.: Gastric mucosal blood flow during pentagastrin-and histaminestimulated acid secretion in the rat. Br. J. Pharmacol. 49, 428-436 (1973)

3 Whittle, B.J.R., Boughton-Smith, N.K., Moncada, S. and Vane, J.R.: Action of prostacyclin $\left(P \mathrm{PI}_{2}\right)$ and its product, 6-oxo-PGF $\mathrm{pa}_{1 \alpha}$ on the rat 
gastric mucosa in vivo and vitro. Prostaglandins 15, 955-967 (1978)

4 Bommelaer, G. and Guth, P.H.: Protection by histamine receptor antagonists and prostaglandin against gastric mucosal barrier disruption in the rat. Gastroenterology 77, 303-308 (1979)

5 Branski, D., Sharon, P., Karmell, F. and Rachmilewitz, D.: Effect of cimetidine on human gastric and duodenal prostanoid synthesis. Scand. J. Gastroenterol. 19, 457-460 (1984)

6 Arakawa, T., Nakamura, H., Chono, S., Saitoh, H., Yanada, H., Ono, T. and Kobayashi, K.: Difference in mode of action of cimetidine and gefarnate on endogenous prostacycline, prostaglandin $E_{2}$ and thromboxane in rat gastric mucosa. Tohoku J. Exp. Med. 140, 407-412 (1983)

7 Mine, T., Yuge, J., Akimoto, K., Yoshida, S., Osawa, H., Hasegawa, Y. and Ogata, E.: Effect of cimetidine and clotiazepam (Rise ${ }^{\mathbb{E}}$ ) on pro- staglandin content in human gastric mucosa Prog. Med. 5, 2837-2842 (1985) (in Japanese)

8 Eastwood, G.L. and Trier, J.S.: Organ culture of human rectal mucosa. Gastroenterology 64, 375-382 (1973)

9 Ohara, S., Ishihara, K., Goso, K. and Hotta, K.: The site of sulfated glycoproteins biosynthesis in rat gastric mucosa. Comp. Biochem. Physiol. 76B, 5-8 (1983)

10 Okada, M., Nagao, S. and Imai, S.: Effect of cimetidine on prostaglandin level and blood flow of gastric mucosa. Proceedings, 12 th Int. Congress of Gastroenterology, Lisbon, p. 105113 (1984)

11 Arakawa, T. and Nakamura, H.: Roles of prostaglandins in the protection of gastric mucosa. In Protection of Gastric Mucosa, Edited by Takemoto, T. and Kobayashi, K., p. 32-44, Ishiyaku Publisher's Irıc., Tokyo (1985) 